\title{
Knowledge Management and Intellectual Capital - A Theoretical Perspective of Human Resource Strategies and Practices
}

\author{
Isniar Budiarti \\ Lecturer of Faculty of Economics, Universitas Komputer \\ Doctoral Student of Management, Universitas Padjadjaran, Bandung - Indonesia
}

\begin{abstract}
:
Significant debates on the role of human resources have been shifted from organizational assets to initiator of innovation and competitive advantages. A current research has investigated suggestive roles of intellectual capital (IC) in strategic human resource management (SHRM) process and human research management (HRM) practices. Conversely, others have shown that the successful management of IC has related to implementation of knowledge management (KM). In turn, those perspectives suggest the implementation and usage of $\mathrm{KM}$ ensure the growth of $\mathrm{IC}$, and the innovative IC may become an effective human resources strategies and practices to acquire innovation and competitive advantages. Through a comprehensive analysis of the latest journals on those concepts, this study argues that human resource strategies and practices involving $\mathrm{KM}$ and management of IC give potential oppurtunities to gain innovation and competitive advantages. Besides, this theoretical perspective suggests organizational culture and leadership style are interrelated to the process.
\end{abstract}

Keywords: intellectual capital, knowledge management, Human resource strategies, Human resource practices.

\section{Introduction}

Today's economic growth represents both business practitioners and scholars dynamic and complex challeges, namely global challenge and stakeholder challenge. Global challenge is determined by globalization, market deregulation in some countries, business cooperation among countries surrounding areas of AFTA and NAFTA for example, and exemption from particular expenses. On the other hand, stakeholder challenge describes consumer's demands for improving high quality of goods and services provided, and for taking organization's social responsibility in business community. Those challenges have reinforced organizations to improve and grow their innovation and competitive advantages in both domestic and international markets (Noe et. al, 2000). Mostly, the forms of innovation and competitive advantages may be manifested through specific and effective business strategies such as producing product innovation, expanding market areas, improving a quality of services and a quality of processes of production, developing better systems of organization, and applying a particular budget saving. These strategies, identified as resource-based view (RBV), implies internal and external aspects, which provides the firm a potential of sustained competitive advantages over other competitors (Kong and Thomson, 2009). Since limitation and similarities of the external aspects - such as natural sources, technology, skillful and professional workers, the internal aspects (namely: human capital, structural capital, relational capital, organizational system, innovation, and knowledge management) offer valuable and uniqueness of the firm to support and develop competitive advantages.

Focusing on rare, imperfectly imitable and non-substitutable characteristics of resources, the internal aspects of the firm such as knowledge management (KM) and intellectual capital (IC) should be the center of strategic analysis (Kong \& Thomson, 2009; Bontis, 2002; Rumelt, 1991; Nelson, 1991). Recent studies suggest knowledge is a critical strategic resource for organization even though some consider the human resources is not specifically deal with developing and supporting competitive advantages. The knowledge remains a valuable asset all employees bring to organizations. For example, Marr et al. (2003, p. 771) argue that successful management of IC is closely linked to the KM processes an organization has in place; which in turn implies that the successful implementation and usage of KM ensure the acquisition and growth of IC. Since misalignment between KM requirements in epistimological terms and individual's perceptions of organizational $\mathrm{KM}$ activities is recognized, understanding the different value pathways and knowledge transformation 
organization may assist to understand the requirement of the groups involved and to design KM processes that grow the IC of organizations. Respectively, other researches have investigated the links between IC and strategic and practical human resources management. For example, Kong and Thomson (2009) point out that strategic human resource management (SHRM) entails on IC. Importantly, human capital exists in human resources in the form of cumulative tacit knowledge and human skills through a sequence of HRM functions such as employee selection, development and deployment (Snell \& Dean Jr., 1992). This suggests that IC as a collective tacit knowledge give potential oppurtunities to gain innovation and competitive advantages through providing an effective SHRM. At its heart, the key strategic questions are what factors may support encompassing an effective intellectual capital management, and what factors trigger knowledge management becomes a potensial asset for growing competitive advantages. Consequently, the knowledge serves valuable and crucial asset for the firm. This idea brings the knowledge become an extension of the RBV; Kong \& Thomson (2009) call it knowledge-based view (KBV).

Simultaneously, an organization should consider KBV to explicitly design a strategic human resource management to have a sustained innovation and competitive advantages. For its intangible asset, IC concept puts knowledge as a logic link to SHRM and HRM. It means that IC plays a prior preparation to adapt challenges and to increase organizational performance in the future. However, these ideas require further studies. As the findings introduce the association between KM, IC, SHRM and HRM, this study focuses on how the KM provides itself as a potential element of IC, and factors that contribute to the creation of valuable and compatible IC. Consequently, this article presents basic arguments and concepts to describe a crucial factor involving KM and IC in developing and growing a represented design of HRM as a uniq SHRM. The description itself is a result in a literature-based analysis; a method that is believed to assist the level of clarity and precesion of an unknown and unclear research area. Finally, this article offers an alternative pathway to a competitive advantage and innovation of the firm.

\section{Knowledge Management}

Since it was issued to be potential asset of the firm, knowledge management $(\mathrm{KM})$ is growing interesting and popular among scholars and practitioners. For instance, Marr et. al. (2003) issue that the creation of KM is closely related to epistimological viewpoints of individual. They have shown that epistimologies differ between individuals and therefore there are divergent views of the knowledge creation process, influenced by the social and cultural context as well as by the ontology of individuals or groups of individuals [Marr et. al. (2003), p. 771].

Following Marr et. al., Fernandez and Sabherwal (2001) claim that knowledge is an individual's reflection and experiences, resulting in inherent knowledge-possessing. It represents through language uses, rules, procedures, and concepts. Practically, individual's knowledge may become organizational knowledge when it is socially constructed and believed by the group of organization. The definition of knowledge in the context of organization may illustrate that: (1) knowledge exists in every individual, group and organization, and (2) knowledge may be considered an asset that can be resided, and a process to know something.

Individual knowledge residing in routines, processes and analysis - argued to be a static internal resource that can be controlled, exploited and traded like most physical resources in an organization (Kong and Thomson, 2009; Kong, 2008) possesses tacit dimension, according to Leonard and Sensiper in Polanyi (1969). Concerning the tacit, Berman et. al. (2002) mention that there are two types of tacit knowledge. Firstly, individual tacit knowledge is one that is connected to a concept of individual's skills and capabilities (Nelson and Winter, 1982; Polanyi, 1969). It is gathered through insinuative pattern owned to unconcious cummulative-experiences which cannot be articulated, and that construct basic valuable human skills. Finally, team-based tacit knowledge, according to Weick and Roberts (1993), is a collective mind; knowledge that comes from group activities and that is memorized as a collective mind. In other words, knowledge of group is defined as individuals' cognitive combinations, or an inhered pattern possessing through collective experiences that are expressed by unconcius sincronic actions while executing intricate tasks in a particular environmental challenge. To sum up, tacit knowledge may reside in many forms and places such as organizational routines, human skills and network relationships within an organization, and it is ultimately members of the organization who embrace it (Kong and Thomson, 2009; Hit et. al., 2001; Grant, 1996). This tacit knowledge is important for the firm because of its relation to individual interaction within an organization. For example, an executive manager who has experienced with a specific case will deal with his fully high performance in the same case without any difficulties in the future. It is identified that the information the manager has becomes tacit knowledge. This tacit knowledge presents a basic element, which increases productivity and competency of individual who is responsible for an assigned task. Thus, human resources become a repository of tacit knowledge (Kong 
and Thomson, 2009; Lado and Wilson, 1994; Tomer, 1987). The processes and practices in which the manager improves his productivity and competency are argued to be a knowledge management (KM). In other words, KM may be understood from its activities, that is, obtaining, developing and sustaining a collective tacit knowledge in organizations.

At prior studies, $\mathrm{KM}$ is concerned primarily with its function to integrate four organizational elements, that are, leadership, organization, technology, and performance. It functions as a potential strategy to create, reach, and improve organizational performance. Respectively, it allows transfering knowledge to support adaptation, sustainability and competency to gain competitive advantages, commitment, improvement of HRM, and of quality of decision, products and services, intellectual asset preserve, implementation of knowledge and new insight (Alawneh et. al., 2009).

Along its development, KM actively involves with managing organizational knowledge to obtain a specific value and to develop competitive advantage and successful performance of the firm. Using the KM, organizations identify their potensial asset of knowledge and implement it to increase work performance and to innovate a brand new product. It implies that to exploit this asset, the organizations should be more responsive to the global and stakeholder challenge, identifying and acquiring qualified knowledge providing external organization.

Latest, KM is recognized as the fundamental activity for obtaining, growing and sustaining IC in organization as SHRM (Kong and Thomson, 2009; Marr et. al., 2003; Marr and Schiuma, 2001). Focusing on the process, in the other sense, KM is considered to be a sistemic prosess to identify, select, manage, and present information in such a way that may feed individual with knowledge. Summarily, KM is a collective phrase for a group of processes and practices used by organizations to increase their value by improving the effectiveness of the generation and application of their IC [Marr et. al. (2003), p. 773]. That imply KM ensures the implemtation of IC as a truly strategy of HRM, and finally the acquisation of business goal.

\section{Intellectual Capital}

Intellectual capital (IC), firstly introduced by an economist John Kenneth in 1969, earns many definitions. Kong and Thomson (2009) view it as an organization's resources including collective tacit knowledge, human skills, experiences and any intellectual resource, which contribute to create value for the organization. Meanwhile, others have defined it as human skills, tacit knowledge, knowledge acquired through information systems (called codified knowledge), and technology used to develoop competitive advantages of organizations (Skandia, 1999 in Bataineh and Al Zoaby, 2011; Kong and Thomson, 2009). In this sense, IC is viewed as a strategic asset for organizational performance, and critical for the competitiveness of organizations (Marr et. al., 2003).

When physical and financial assets which are no longer the strategic assets to facilitate competitive advantage, IC pays considerable attention to provide a competitive market position to an organization (Kong and Thomson, 2009; Teece, 2002). It means that the IC concept ensures the process of creation value to stakeholders and organizations. It is compatible with four attributes for the firm: rare, valuable, costly to imitate and non-substitutable (Kong and Thomson, 2009).

The theoretical framework of IC was firstly developed as a worksheet to analyze contributions fo intangible asset value of an organization (Sveiby, 1997 in Bataineh and Al Zoaby, 2011). However, its development leads to a strategic-based perspective, which allows the organization to identify and evaluate a main competency required to gain continuative and sustained competitive advantages (Viedma, 2003). Mainly, the importance of IC has enlightened about: (1) the revolution of information technology and social information; (2) the improvement of the roles of knowledge and knowledge-based economy; (3) the changement of interpersonal and networking operational patterns; and (4) the creation of innovation and creativity as key factors for organizational performance and competitiveness (Guthrie, 2001 in Rambe, 2012). Following the work of a number of scholars in the field of IC, the concept of IC covers three primary interrelated indicators: human capital, structural capital, and relational capital (Kong and Thomson, 2009; Borneman et. al., 1999 in Fathi, 2013).

Human capital contends knowledge, human skills, competency, attitude, behaviour and personal experiences as employee. It exists in human resources in the form of cumulative tacit knowledge and human skills through a sequence of HRM functions such as employee selection, development and deployment (Kong and Thomson, 2009; Snell and Dean Jr., 1992). The IC concept views human resources as a key operational factor to support and contribute a dynamic creation value in day-to-day activities, and to develop a best performance of the firm. Human capital, as an cumulative capabilities in an organization, may assist to give best solution to business problems. However, Kong and Thomson (2009) have indicated that despite of increasing the stock of human capital when new employees join an organization, the human capital embodied 
in the new employees is not firm specific. They should encounter a period of dynamic adjustment cost to fit the new environment. Kong and Thomson (2009) have also mentioned the influence of new employees' prior industry experience. According to them, their experiences may affect their performance, preventing them to unlearn and re-learn knowledge in the environment. In other words, organizations should pay attention more on managing human capital.

Following the work of Kong and Thomson (2009), the role of human resource in creating and growing the competitive advantage depends highly on the other two IC indicators: structural capital and relational capital. They argue that employees' know-how is most inimitable when it is firm specific and resides in the organization where it was originally developed. The structural capital, as a supportive infrastucture for human capital, refers to exploitation and manifestation of human capital when he is conducting his functions to increase organization's income and values adding to its assests. Simply it is knowledge that remains in an organization. The structural capital deals with general systems and procedures to cope business problems and to create innovation (Chu et.al., 2006 in Alipour, 2012). Further, structural capital describes organizational composition and organizational structure that bring to creation, development, and exploration knowledge. The firm may not optimalize its intellectual capital of human resources if it does not have specific sistemic systems and procedures (Shiddiq, 2013). Shortly, it is a mechanism and structure of organizations. Because of its complexity, the structural capital may be classified into innovative capital, process capital, and organizational capital. Other structural capital elements considered are organizational culture and routines. Kong and Thomson (2009) claim that both elements may help organizations to amplify human capital, to increase firm specifically and to decrease imitability. Consequently, HRM managers should consider structural capital when they are formulating and implementing a particular HRM strategy and practice. Kong and Thomson (2009) describe structural capital includes all of the non-human storehouses of knowledge in organizations such as database, routines, organizational culture and anything that creates value for organization.

In doing the business, an organization does interact with external stakeholders. Representing the exchange of knowledge between an organization and its external stakehoders, relational capital acts as a multiplying element creating values for the organization by connecting human capital and structural capital with other external agents [Kong and Thomson, (2009), p. 360]. The relational capital, also called customer capital, represents embedded-into capability knowledge that is used when individual interaction takes place, or knowledge that exists in business networks (Nahapiet and Ghosal, 1988 in Bataineh and Zoaby 2011). Briefly, the relational capital is an organization's relations with its external stakeholders and the perceptions that they hold about the organization, as well as the exchange of knowledge between the organization and its external stakeholders (Kong and Thomson, 2009). The capital involves knowledge improvement on customers, stakeholders, distributors, industrial associations (government) and society. As a result, this capital serves as comprehensive knowledge about marketing and customer relations. Relational qualities and capabilities of inviting new customers are keys to gain successful organization (Montequin et al., 2006 in Alipour, 2012). According to Kong and Thomson (2009), the relational capital helps members of an organization to appreciate the dynamic of external knowledge. This external knowledge is important to the roles of human resources in increasing the stock human capital and in potentially improving the quality of existing human capital within the organization.

The concepts of IC indicators illustrate that relational capital such as the loyalty of customers, the mutual trust and commitment of suppliers, the reputation and relationship that an organization has developed over time, may be built when human capital and structural capital have been optimized. Human capital as a main source of IC, suggested by Bontis (2004), provides a number of silent intellectual values that potentially support organizational routine activities. These routine activities produce knowledge that remains in an organization. The resided knowledge may assist individuals in their quest for optimum intellectual performance (Kong and Thomson, 2009). Simply, individual creativities, resulting in his intellectual knowledge both human capital and structural capital, increase loyalty, trust, commitment, reputation and relationship (relational capital), so that the performance of the organization may improve significantly. Consequently, the organization receives high financial incomes and sustained competitive advantages.

To sum up, IC may be defined and exploited as other physical resources. In spite of its elusive characteristic, IC may give organization new internal resources that potentially create competitive advantages (Bontis, 1996). That shows the organization operates its activity effectively when intellectual properties of individuals, infrastructures and intangible assets of customer are interrelated in the activity of human resources (Brooking, 1996). In this case, IC is defined as intellectual material (knowledge, information, intellectual properties, and experiences) that can be used to create prosperity. It may also be considered as a useful collective knowledge (Stewart, 1997). 


\section{Human Resource Strategies and Practices}

A concept requires a strategic framework in its implementation. For example, individual tacit knowledge may contribute its functions to organizational business plan when it is managed properly. Knowledge management (KM), a main topic of KBV, aims to provide learning organization to compete and challenge the growing economic change. In this case, KM serves the organization a strategic framework to exploit its resources, especially internal resources: tacit knowledge and IC.

As Kong and Thomson's argumentation (2009), HRM has received a legitimate relevance to strategy research based on the research-based view (RBV) of the firm, which is increasingly developed in 1990s. According to RBV, human resources play an important role in obtaining, growing and sustaining firm competitiveness. Stressing on knowledge as a critical strategic resource for organizations (KBV perspective), KM encourages knowledge transfer, supports knowledge sharing, and re-use it to create values (Kong \& Thomson, 2009; Duffy, 2001). KBV creates a new view that knowledge is dynamic, evolving, quasi-autonomous system of knowledge production and application (Spender, 1996). That leads to an assumption that knowledge is a static internal resource that can be controlled, exploited and traded like physical resources in organizations (Kong \& Thomson, 2009).

Supporting Colbert's theories, Kong and Thomson (2009) generate HRM strategy involves two assumptions. Firstly, individual tacit knowledge of employee provides the foundation for strategy formulation and the means for strategy implementation in an organization (Kong \& Thomson, 2009). Secondly, HRM practices of the organization serve a crucial means to develop the strategy capability of its human resources (Kong \& Thomson, 2009). It implies that the role of human resources in creating organizational advantages is manifested through the interrelated collective knowledge of employee to HRM strategies and practices (Hatch \& Dyer, 2004).

According to HRM strategy, organizations should bring all parties to have tacit knowledge. With the supports of organizations, individual's knowledge may create human values. It seems that the individual begins to creatively think positive actions, which can contribute to organizations. The organization may control and exploit it by publishing etique codes, but by still giving individual opportunities to make his own decision. Individual tacit knowledge should be appreciated by himself, others, and related parties. Tacit knowledge may lead organizations to comprehensively understand their goals.

Furthermore, the ultimate objective of HRM in organizations is to encourage members of organizations to understand organizational existence and to learn effective and potential strategies to reach the goals. The successful HRM of an organization is identified by its consistency in developing new knowledge, sharing it in its operating environment, and adapting it in its technology, products and services. This is explicitly recognized that knowledge shoud be maintained, so that sense of team emphasized team's sense of belonging may be created, and the roles of knowledge can be optimized. Forms and capabilities of KM influence greatly on the quality of knowledge and on the quality of relationship and integration other elements of HRM.

Other studies on HRM have resulted in the importance of integrated strategy involving individual tacit knowledge and socialculture of an organization. This integration is believed to pursue the creation of sustained innovation. The concept of intangible asset, know-how-based organizations, and learning organization are frequently debated from the late 1980s to the early 1990s. In addition, statistics showed there were a significant numbers of organizations' interests on implementation of KM. In 1997, for example, there were 28 percent of organizations in USA and Europe had already implemented KM strategy, 50 percent made a preparation, and 93 percent planned it (Smith \& Farquhar, 2000).

$\mathrm{KM}$ is implemented to manage information and knowledge that are structured in an organization. Because of that, the main purpose of the implementation of KM is to improve communication among individuals and quality of decision, so that it will accelerate new development, better and faster work result, high incorporative degree, and satisfaction of customers. A better communication among individuals in an organization, especially communication of tacit knowledge, initiates better organizational performance and arganizational sustainabilities.

As argued by Marr et. al. (2003), the central to all KM applications are that human beings provide themselves with different perceptions and philosophies. Besides, socio-cultural contexts differ from one to others. Those issues lead to conclusion that no two KM implementation will be the same. For instance, an organization with its own specific knowledge and its unique challenges will apply a particular KM that shows a specific process and activity, and that has different indicators of success. The design of KM will be determined by its unique elements of KM. One of KM elements relates to human resources with knowledge, ideas, skills and experiences. Thus, human resource is an unlimited and imperfectly imitable 
strategic asset for an organization. This asset along with technology and organizational culture offer effectiveness of productivity and competence to success over others.

\section{The Relationships of Knowledge Management, Intellectual Capital, Human Resource Strategy and Practices}

As argued by Kong and Thomson (2009), the IC concept presents knowledge to three primary interrelated indicators of IC. These three IC indicators, namely human capital, structural capital and relational capital, suggest a structured framework for HRM strategies and practices, which an organization applies to improve its performance (Roos, 1998). However, IC should be conceptualized in the role of human resources for optimal organizational performance (Kong \& Thomson, 2009). In other words, management of IC involves knowledge assets that are gathered, built and maintained in organizations through KM.

KM, defined by Marr et. al. (2003), is the phase for a group of processes and practices to increase organizational's values by improving the effectiveness of the generation and application of its intellectual capital. Since KM processes cannot be observed like physical processes, management of IC should be visualized to explain the contribution human resources to organizational performance.

The first point is that epistimological viewpoints differ between individuals. As a result, the knowledge creation processes leads to different views. These processes are influenced by social and cultural context as well as the ontology of individuals or group of individuals (Marr et. al., 2003). It seems that knowledge is socially constructed. Therefore, the design and application of KM differ from one organization to the others. Furhermore, organizational goals influence greatly on KM, a supportive strategy.

Being a competitive edge for an organization, a collective tacit knowledge, human skills, experiences, and other intellectual resources are managed effectively. The management of this IC may be examined through visualization proposed by Marr at. al. (2003). In the first step of Marr et. al.'s visual representation, identification of the key IC resources in an organization is executed to create values to gain strategic performance of the organization. Knowledge assets (see figure 1), as an identified IC resources, determine the strategy development. In this case, a manager should consider all IC resources before designing HR strategy and practices.

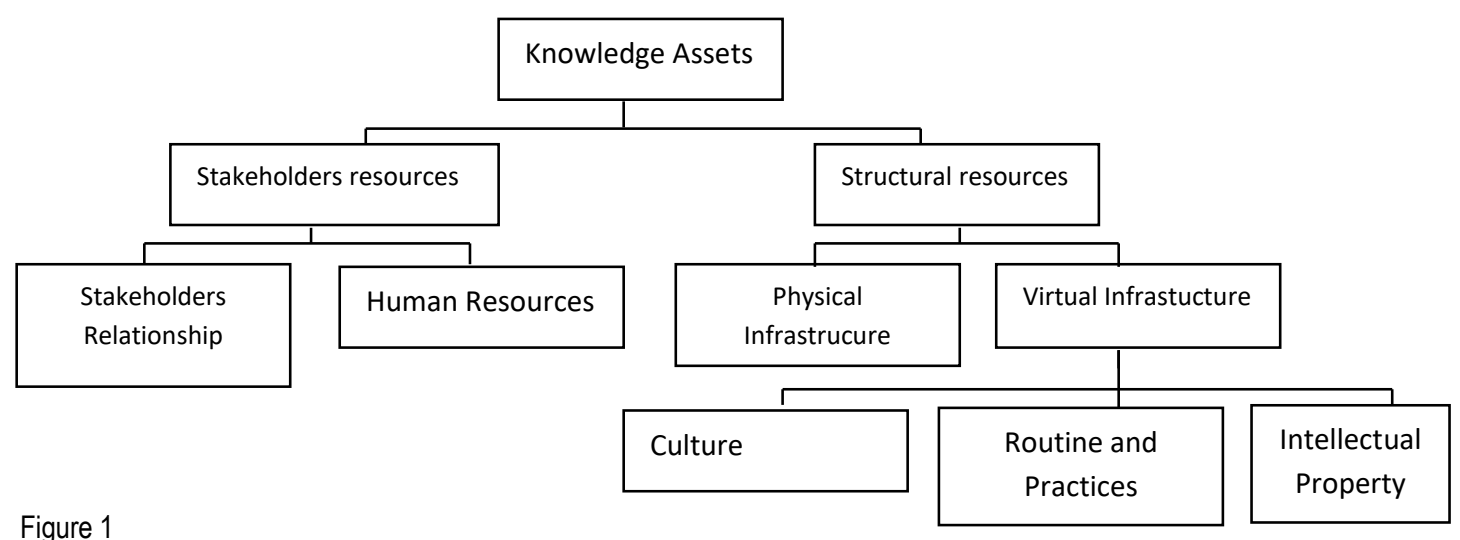

Classification of knowledge assets

Sources: Marr et. al. (2003)

The second step is to visualize the value creation pathways and transformation of key IC. It means that the visual representation shows the causal relationships of business logic that may lead to the achievement of the strategic objectives and the satisfaction of stakeholders. Then the third step is to measure performance through indicators that can be developed from the value creation. The performance indicators may provide a prediction that illustrates how the business works. After activities of identifying, mapping and measuring, at following stage, a manager decides whether cultivate and nurture the existing IC using KM processess or whether the assumption of value creation were wrong in which case they 
have to go back to step one and identify the real drivers of success (Marr et. al., 2003). Similarly, the understanding of different value creation assists an organization to formulate KM processes that best suit the epistemologies of its employee to ensure effective and efficient system to manage its knowledge (Marr et. al., 2003).

In order to achieve organizational performance intended, there are some points to be considered. Firstly, as mentioned before, no KM will be the same since individual perception of organizational management activities differ from an organization to others. Consequently, the organization should consider social-cultural contexts involved, and make knowledge socially constructed. That indicates the social environment play a certain role in implementation of KM. Secondly, tacit knowledge of individuals may not be transferred so that knowledge sharing is an alternative to communicate information in the organization. However, knowledge sharing is not easy as sound. It requires willingness of the individuals. Clearly, the attitude of individuals plays an important role to the success of sharing activities. Since individual tacit knowledge and individual attitudes are greatly influenced by his perceptions on knowledge, KM is formulated to answer those challenges. Thirdly, the formulated KM may involve explicit knowledge embodied in procedure and cognitive process. In this case, it is suggested that self-generated to knowledge based is controlled by a certain process to ensure that there will not be unexpected or unwanted consequences of the changes. This condition may be created through communicating and implementing a specific and unique organizational culture, which defines the boundaries of the organizational in a manner. The organizatonal culture facilitates individual interaction by limiting the scope of information processing to appropriate level (Ogbonna \& Harris, 2000). Fourthly, the organizational culture will be implemented successfully if leadership style is involved in the process. As Ogbonna and Harris (2000) suggested, leadership style may determine whether success of failure of a group, organization or even a country. Of course, it is suggested that one way to cope with the increasing volatility and turbulance of external environment is by training and developing leaders and equipping them with skills (Ogbonna \& Harris, 2000). Finally, a crucial skill the leader requires is the skill of communication that is represented through language choice and use.

In conclusion, the environment within which the organization operates will influence the design of organizational strategy. In other words, industry, culture and economic condition will determine the HR strategies and practices of an organization. At the end, the environment and organizatonal strategy decide whether the organization performs well as expected.

\section{Conclusion}

Understanding the relationship between human resources of an organization and its performance may lead to the achievement of organizational innovation and competitive advantages. That also means the maximum effectiveness of the organizational performance may be achieved. However, human resources and organizational performance is not directly related. The concepts of IC, KM, and HR strategies and practices are involved in the process.

This article suggests that the implementation and usage of $\mathrm{KM}$ ensure the growth of $\mathrm{IC}$, and the resulted IC plays important role in human resource strategies and practices to reach innovation and competitive advantages. Furthermore, the implementation of $\mathrm{KM}$ as the fundamental activity for obtaining, growing and sustaining IC in organizations, will be effective if the organizations consider deeply to the differences of socio-cultural contexts and individual perceptions on knowledge. To decrease the differences, it is suggested that the organizations should establish their specific organizational culture and should invest a good leader to cope with the increasing volatility and turbulance of external environment. Finally, communication skills, specifically language choice and use, are suggested to reduce unwanted and undesirable conflicts in executing a leadership.

\section{References}

[1] Alawneh, A.A., Abuali, A., \& Almarabeh, T.Y (2009) 'The Role of Knowledge Management in Enhancing theCompetitiveness of Small and Medium-Sized Enterprises (SMEs)', Communications of the IBIMA,Vol. 10, pp. 98-109

[2] Alipour Mohammad (2012) 'The effect of intellectual capital on firm performance: an investigation of Iran insuran ce companies', Measuring Business Excellence,Vol. 16, No. 1, pp. 53-66, Emerald Group Publishing

[3] Bataineh, Mohammad. T. and AI Zoaby, Mohammad (2011) 'The Effect of Intellectual Capital on Organizational Competitive Advantage: Jordanian Commercial Banks (Irbid District) An Empirical Study', Euro Journals, Inc.-International Bulletin of Business Administration

[4] Bontis, N. (1996) 'There's a Price on Your Head: Managing Intellectual Capital Strategically', BusinessQuartely, Summer, pp. $40-47$ 
[5] Bontis, N. (2002) 'Managing Organizational Knowledge by Diagnosing Intellectual Capital: Framing and Advancing the State of the Field', In The Strategic Management of Intellectual Capital and Organizational Knowledge (hoo CW and Bontis N, Eds), pp 621-642.

[6] Bontis, N. (2004) 'National Intellectual Capital Index: a United Nations initiative for the Arab region', Journal of Intellectual Capital, Vol. 5 No. 1, pp. 13-39.

[7] Brooking, Annie (1996) IC: Cone Assets for Rhird Millenium Eterprose, London-England: Thomson Business Press.

[8] Chu, S. K. W., Chan, K. H., and Wu, W. W. Y. (2006) 'Charting Intellectual Capital Performance of The Gateway to China', Journal of Intellectual Capital, 12 (2) pp. 249-276.

[9] Duffy, J (2001) 'Managing Intellectual Capital. Information Management Journal 35(2), p. 59-63.

[10] Fathi Saeed, Dr., Farahmand Shekoofeh, Dr., Khorasani Mahnaz (2013) 'Impact of Intellectual Capital on Financial Performance', International Journal of Academic Research in Economics and Management Sciences,Vol. 2, No. 1, ISSN: 2226-3624

[11] Fernandez B, Gonzalez, A., and Sabherwal, R. (2001) Knowledge Management:Challenge, Solutions, and Technologies. Prentice Hall.

[12] Hatch, N.W. and Dyer J.H. (2004) 'Human Capital and Learning as a Source of Sustainable Competitive Advantage, Strategic Management Journal 25(12), p. 1155-1178.

[13] Kong, Eric (2008) 'The Development of Strategic Management in Non-profit Context: Intellectual Capital in Social Service Non-profit Organizations, Internal Journal of Management Reviews 10(3), p. 281-299.

[14] Kong, Eric, and S. Bruce Thomson (2009) 'An Intellectual Capital Perspective of Human Resource Strategies and Practices', A Journal of Knowledge Management Research \& Practice, Vol. 1 No. 1, pp 356-364

[15] Lado, A.A. and M.C. Wilson (1994) 'Human Resource Systems and Sustained Competitive Advantage: A Competencybased Perspective. Academy of Management Review 19(4), p. 699-727.

[16] Marr, Bernard and Schiuma, G. (2001) 'Measuring and Managing Intellectual Capital and Knowledge Assets in New Economy Organisations", in Bourne, M. (Ed.), Handbook of Performance Measurement, Gee, London.

[17] Marr, Bernard et. al. (2003) Intellectual Capital and Knowledge Management Effectiveness, In A Journal of Management Decision, 41 (8) [online], ISSN: 1125-1747, pp. 771-781 http://www.emeraldinsight.com/researchregister

[18] Nelson, R.R. (1991) 'Why do firm differ, and how does it matter?' Strategic Management Journal. No. 12 (Winter Special Issue), pp 61-74.

[19] Ogbonna, Emmanuel and Lloyd C. Harris (2000) 'Leadership Style, Organizational Culture and Performance: Empirical Evidence from UK Companies. International Journal of Human Resource Management 11(4), p. 766-788.

[20] Polanyi, M. (1969) The tacit dimension, London: Reutledge dan Kegan Paul.

[21] Rambe, Rizki Fillhayati (2012) 'Pengaruh Intelllectual Capital Terhadap Kinerja Keuangan Perusahaan Perbankan yang Terdaftar di BEl', Jurnal Keuangan dan Bisnis, Vol. 4, No.3

[22] Roos, J. (1998) 'Exploring the Concept of Intellectual Capital (IC), Long Range Planning 31(1), p. 150-153.

[23] Rumelt, R.P. (1991) 'How much does industry matter?' Strategic Management Journal, Vol. 12 No. 3, pp 167-185.

[24] Smith, Sandy G. (2000) 'The Essential Qualities Of A Home', Journal of Environmental Psychology (1994) 14, 31-46. Academic Press Ltd.

[25] Snell, S.A. and Dean Jr. J.W. (1992) Integrated Manufacturing and Human Resource Management: A Human Capital Perspective. Academy of Management Journal Vol. 35 No. 3, 467-504.

[26] Spender, J.C. (1996) 'Making Knowledge the Basis of a Dynamic Theory of the Firm, Strategic Management Journal 17(Winter Special Issue), p. 45-62.

[27] Stewart, A.T. (1997) Intellectual Capital, The New Wealth of Organizations, New York: Bantam Doubleday Publishing

[28] Sveiby, K.E. (1989) The Invisible Balance Sheet. http://www.sveiby.com/Articles/ IntangAss/DenOsynlinga.pdf.

[29] Teece, D.J. (2002) Managing Intellectual Capital: Organizational Strategic, and Policy Dimensions, Oxford University Press, Oxford.

[30] Tomer, J.F. (1987) Organizational Capital: The Path to Higher Productivity and Well-being, Prieger Publishers, New York.

[31] Viedma, José María Martí (2003) 'In Search of an Intellectual Capital General Theory', Electronic Journal on Knowledge Management, Volume 1 Issue 2. 213-226 